\title{
Three generations of epidermal growth factor receptor tyrosine kinase inhibitors developed to revolutionize the therapy of lung cancer
}

This article was published in the following Dove Press journal:

Drug Design, Development and Therapy

24 November 2016

Number of times this article has been viewed

\author{
Haijun Zhang \\ Department of Oncology, \\ Zhongda Hospital, Medical School, \\ Southeast University, Nanjing, \\ People's Republic of China
}

\begin{abstract}
Lung cancer, $\sim 80 \%-85 \%$ of which is non-small-cell lung cancer (NSCLC), is the leading cause of cancer-related mortality worldwide. Sensitizing mutations in epidermal growth factor receptor $(E G F R)$ gene $\left(E G F R \mathrm{~m}^{+}\right)$, such as exon 19 deletions and exon 21 L858R point mutations, are the most important drivers in NSCLC patients. In this respect, small-molecule EGFR tyrosine kinase inhibitors (TKIs) have been designed and developed, which launched the era of targeted, personalized and precise medicine for lung cancer. Patients with $E G F R \mathrm{~m}^{+}$ could achieve good responses to the treatment with the first-generation EGFR TKIs, such as erlotinib and gefitinib. However, most patients develop acquired drug resistance mostly driven by the T790M mutation occurring within exon 20. Although the second-generation EGFR TKIs, such as afatinib, dacomitinib and neratinib, demonstrated promising activity against T790M in preclinical models, they have failed to overcome resistance in patients due to dose-limiting toxicity. Recently, the third-generation EGFR TKIs have shown to be effective against cell lines and murine models harboring T790M mutations while sparing wild-type EGFR, which represents a promising breakthrough approach in overcoming T790M-mediated resistance in NSCLC patients. This article provides a comprehensive review of the therapy revolution for NSCLC with three generations of EGFR TKIs.
\end{abstract}

Keywords: lung cancer, epidermal growth factor receptor, tyrosine kinase inhibitors, T790M mutation

\section{Introduction}

Lung cancer, $\sim 80 \%-85 \%$ of which is non-small-cell lung cancer (NSCLC), is the leading cause of cancer-related mortality around the world. ${ }^{1}$ Due to poor prognosis with traditional chemotherapy agents, the discovery of molecular changes that drive lung cancer leads to a dramatic shift in the therapeutic landscape of this disease. The epidermal growth factor receptor (EGFR) represents an important signaling pathway that regulates tumorigenesis, invasion and metastasis of tumor. The most important drivers in NSCLC patients are mutations in EGFR gene, which occur in $\sim 10 \%-35 \%$ of NSCLC patients. ${ }^{2,3}$ The so-called sensitizing mutations in $E G F R\left(E G F R \mathrm{~m}^{+}\right)$usually refer to exon 19 deletions and exon 21 L858R point mutations. In this respect, smallmolecule EGFR tyrosine kinase inhibitors (TKIs) have been designed and developed for the targeted and personalized therapy selection on molecular characteristics of tumors while avoiding a "one-size-fits-all" chemotherapy approach. ${ }^{2}$ Patients with $E G F R \mathrm{~m}^{+}$ could achieve good responses to the treatment with the first-generation EGFR TKIs, such as erlotinib and gefitinib. ${ }^{4,5}$ Unfortunately, despite initial benefit, most patients develop acquired resistance to them within 1 year, which is driven in $\sim 60 \%$ of cases
Correspondence: Haijun Zhang Department of Oncology, Zhongda Hospital, Medical School, Southeast University, 87 Dingjiaqiao, Nanjing 210009, People's Republic of China Tel/fax +86 2583275418

Email zhanghaijunseu@।63.com 
by a second-site EGFR point mutation, the T790M mutation occurring within exon 20.6,7 Although the second-generation EGFR TKIs, such as afatinib, dacomitinib and neratinib, demonstrated promising activity against T790M in preclinical models, they have failed in clinical trials due to dose-limiting toxicity. ${ }^{8-10}$ Recently, the third-generation EGFR inhibitors, including osimertinib, rociletinib and olmutinib, have been developed, which could more effectively target T790M while sparing wild-type EGFR. ${ }^{11}$ These mutant-selective EGFR TKIs could represent a promising approach of overcoming T790M-mediated resistance in NSCLC patients. For example, osimertinib has been classed as a breakthrough compound for fast-track development and received its first global approval by the US Food and Drug Administration (FDA) in November 2015 for patients with metastatic EGFR T790M-positive NSCLC who had progressed on prior systemic therapy, including an EGFR TKI. ${ }^{12}$

To date, three generations of small-molecule EGFR TKIs have been designed and developed, whose formula, systematic name and structure are listed in Table 1. The purpose of this article is to provide a comprehensive review of the therapy revolution for NSCLC with these EGFR TKIs, from the early successes with the first-generation EGFR TKIs to the breakthrough in overcoming resistance with the second- and third-generation ones.

\section{First-generation EGFR TKIs Erlotinib}

Erlotinib was the first FDA-approved EGFR TKI for the targeted therapy of NSCLC patients. In the Canadian phase III BR.21 trial, patients with stage IIIB or IV NSCLC who had received one or two chemotherapy regimen were randomized to erlotinib or placebo. The results demonstrated that the response rate was $8.9 \%$ in the erlotinib group and $<1 \%$ in the placebo group $(P<0.001)$. Progression-free survival (PFS) of erlotinib and placebo was 2.2 months and 1.8 months, respectively (hazard ratio $[\mathrm{HR}]=0.61, P<0.001$ ). Overall survival (OS) of erlotinib and placebo was 6.7 months and 4.7 months, respectively ( $\mathrm{HR}=0.70, P<0.001)$. This trial is the first clinical trial to show a significant improvement in OS comparing erlotinib to placebo. ${ }^{13}$

\section{Gefitinib}

The Iressa Pan-Asia Study (IPASS) randomized $>1,200$ untreated patients with stage IV NSCLC to compare first-line gefitinib to the combination of carboplatin and paclitaxel. The 12-month rates of PFS of gefitinib and carboplatinpaclitaxel were $24.9 \%$ and $6.7 \%$, respectively. What is more, for patients with $E G F R \mathrm{~m}^{+}$, PFS was significantly longer among those who received gefitinib than among those who received carboplatin-paclitaxel (HR for progression or death $=0.48, P<0.001$ ), whereas for patients with negative EGFR mutations, PFS was significantly longer among those who received carboplatin-paclitaxel (HR for progression or death with gefitinib $=2.85, P<0.001)$. This trial is the first trial to demonstrate that EGFR TKI is superior to chemotherapy as an initial treatment for NSCLC patients with $E G F R \mathrm{~m}^{+} .{ }^{14}$ Similar results have been achieved in other trials, such as the First-SIGNAL trial from South Korea, the OPTIMAL trial from China and the EURTAC trial from Europe. ${ }^{15-17}$

\section{Icotinib}

Icotinib is also an oral, small-molecule EGFR TKI for NSCLC, which is approved in China. A phase III, doubleblind, non-inferiority trial (ICOGEN) compared icotinib to gefitinib in unselected Chinese patients with advanced NSCLC who had not responded to one or more platinumbased chemotherapy regimen. In this trial, patients were randomly assigned to either icotinib or gefitinib. The results demonstrated that icotinib was non-inferior to gefitinib in terms of PFS at 4.6 months vs 3.4 months, respectively. Thus, icotinib is also a treatment option for pretreated patients with advanced NSCLC. ${ }^{18}$

These studies confirmed that the first-generation EGFR TKIs were effective for patients with $E G F R \mathrm{~m}^{+}$NSCLC in the first-line setting.

\section{Second-generation EGFRTKIs}

After initial benefit, most patients develop resistance to the first-generation EGFR TKIs mostly driven by T790M mutation. Thus, the second-generation EGFR TKIs, such as afatinib, dacomitinib and neratinib, are designed to overcome the acquired resistance.

\section{Afatinib}

Afatinib (BIBW 2992), an aniline-quinazoline, is an irreversible EGFR TKI. In a phase I study, three patients with NSCLC achieved a durable partial response to afatinib, including two EGFRm ${ }^{+}$patients. ${ }^{19}$ In the trial of LUX-Lung 1, patients with $E G F R \mathrm{~m}^{+}$NSCLC who had received a firstgeneration EGFR TKI and chemotherapy were randomized to either afatinib or placebo. PFS of afatinib and PFS of placebo were 3.3 months and 1.1 months $(P<0.0001)$, respectively. Afatinib could be of some benefit to patients who have failed in previous EGFR TKI treatment. ${ }^{20}$ Then, the drug was studied as a first-line treatment for $E G F R \mathrm{~m}^{+}$NSCLC 
Table I Formula, systematic name and structure of small-molecule EGFR TKIs




Table I (Continued)

\begin{tabular}{llll}
\hline $\begin{array}{l}\text { Generic } \\
\text { name }\end{array}$ & $\begin{array}{l}\text { Trade } \\
\text { name }\end{array}$ & Formula & Systematic name \\
\hline Rociletinib & & $\mathrm{C}_{27} \mathrm{H}_{28} \mathrm{~F}_{3} \mathrm{~N}_{7} \mathrm{O}_{3}$ & $\begin{array}{l}\mathrm{N} \text {-[3-[[2-[4-(4-acetylpiperazin-I-yl)-2- } \\
\text { methoxyanilino]-5-(trifluoromethyl) } \\
\text { Pyrimidin-4-yl]amino]phenyl]prop-2- } \\
\text { enamide }\end{array}$ \\
\hline
\end{tabular}

Abbreviations: EGFR, epidermal growth factor receptor; TKI, tyrosine kinase inhibitor.

in a phase II study (LUX-Lung 2). Overall, a response was noted in $79(61 \%)$ of 129 patients. In all, $70(66 \%)$ of the 106 patients with common exon 19 deletions and exon 21 L858R point mutations demonstrated a response, as did nine (39\%) of 23 patients with less common EGFR mutations. ${ }^{21}$ Afatinib could significantly prolong PFS as compared with the pemetrexed plus cisplatin chemotherapy, at 11.9 months vs 6.9 months $(P<0.001)$, as first-line treatment for $E G F R \mathrm{~m}^{+}$ NSCLC patients in a global phase III study, LUX-Lung 3. Objective response rate (ORR) was also significantly higher with afatinib than that with chemotherapy (56\% vs $23 \%$, $P<0.001)$. Thus, afatinib was approved as the first-line treatment for advanced NSCLC patients with $E G F R \mathrm{~m}^{+}{ }^{8}$

\section{Neratinib}

In vitro, neratinib showed activity against $E G F R \mathrm{~m}^{+} \mathrm{NSCLC}$ cell lines, including ones harboring a T790M. ${ }^{22}$ However, a phase II trial demonstrated disappointing results with an ORR of $3 \%$ in patients with EGFRm ${ }^{+}$NSCLC and no responses in patients with wild-type EGFR, which resulted from insufficient bioavailability from diarrhea-imposed dose limitation. $^{23}$

\section{Dacomitinib}

Dacomitinib (PF-00299804) is another second-generation irreversible $\mathrm{TKI}^{24} \mathrm{~A}$ phase II study of dacomitinib in treatment-naïve advanced NSCLC patients with either $E G F R \mathrm{~m}^{+}$or clinical characteristics associated with $E G F R \mathrm{~m}^{+}$ found an ORR of $53 \%$ and a median PFS of 11.5 months. ${ }^{25}$ However, a phase III study (NCIC CTG BR.26) compared dacomitinib with placebo in patients with advanced NSCLC pretreated with cytotoxic chemotherapy and an EGFR-TKI failed to meet its primary objective of prolonging OS. ${ }^{26}$ Thus, dacomitinib cannot be recommended for treatment of NSCLC patients previously treated with chemotherapy and an EGFR TKI.

\section{Third-generation EGFR TKIs}

So far, EGFR TKIs have been widely used in NSCLC patients. However, acquired resistance to most clinically available EGFR TKIs has been mediated by T790M. As mentioned earlier, although the second-generation EGFR TKIs show promising activity against T790M in vitro, they have failed in patients due to serious side effects. Thus, therapeutic strategies for NSCLC patients with the acquired resistance to EGFR TKIs mediated by T790M are still limited. More efforts should be focused on new-generation EGFR TKIs that could more effectively target T790M while sparing wild-type EGFR. Recently, a novel class of third-generation EGFR TKIs, such as osimertinib, rociletinib and olmutinib, has been designed and developed to overcome T790M-mediated resistance. For example, osimertinib received its first global approval by FDA in November 2015 for patients with metastatic EGFR T790M-positive NSCLC who had progressed on prior systemic therapy, including an EGFR TKI.

\section{Osimertinib}

Osimertinib, also known as AZD9291, is a novel EGFR TKI developed by AstraZeneca, which shows 200-fold selectivity for T790M/L858R protein over wild-type EGFR. ${ }^{27,28}$ It has been classed as a "breakthrough" compound for fast-track development, having demonstrated perfect ORR in T790Mpositive NSCLC patients who had progressed on a firstgeneration EGFR TKI. ${ }^{27,28}$ The efficacy of osimertinib for the treatment of patients with locally advanced or metastatic $E G F R \mathrm{~m}^{+} \mathrm{NSCLC}$ has been investigated in several clinical trials. The phase I AURA trial was initiated to assess the safety and efficacy of osimertinib in patients with locally advanced or metastatic $E G F R \mathrm{~m}^{+}$NSCLC who had documented disease progression while receiving a first- or second-generation EGFR TKI. ${ }^{29}$ The result demonstrated that ORR was $51 \%$. Of the 127 patients with confirmed EGFR T790M, osimertinib was associated with an ORR of $61 \%$, while those with 
no detectable EGFR T790M mutation (n=61) had an ORR of $21 \%$. The median PFS was 9.6 months in EGFR T790Mpositive patients and 2.8 months in EGFR T790M-negative patients. Based on these data, in April 2014, osimertinib was granted breakthrough therapy designation by the FDA for the treatment of patients with NSCLC and EGFR T790M mutation whose disease has progressed during treatment with a TKI. Osimertinib was further evaluated in patients with EGFR T790M-positive NSCLC and progression after EGFR TKI therapy in a phase II extension cohort of AURA and an additional phase II trial. Results from a data cutoff on November 1, 2015, for pooled analysis of two phase II studies showed that ORR was $66 \%$, median duration of remission (DOR) was 12.5 months, median PFS was 11.0 months and the proportion of patients progression free at 12 months was $47.5 \%{ }^{30}$ Thus, osimertinib received its first global approval on November 13, 2015, for patients with metastatic EGFR T790M-positive NSCLC who have progressed on, or after, EGFR TKI therapy in the USA. Now, several phase III trials are ongoing in evaluating osimertinib as second-line treatment in EGFR T790M-mutated NSCLC and first-line treatment for NSCLC with any EGFRm ${ }^{+}$.

\section{Rociletinib}

Rociletinib (CO-1686) is also a small-molecule, irreversible, mutant-selective third-generation EGFR TKI. ${ }^{31}$ A phase I/II study enrolled a total of 130 patients with EGFR-mutated NSCLC who had disease progression during previous treatment with an existing EGFR inhibitor. ORR among the 46 patients with T790M positive mutation was $59 \%$, and the rate among the 17 patients with T790M negative mutation was $29 \%$. The median PFS at the time of analysis was 13.1 months and 5.6 months for patients with and without T790M mutations, respectively. The results demonstrated that rociletinib was active in NSCLC patients with $E G F R \mathrm{~m}^{+}$ associated with the T790M resistance mutation. ${ }^{32}$

\section{Olmutinib}

In a phase I/II study of olmutinib (HM61713), another thirdgeneration EGFR TKI, in patients with advanced NSCLC who had failed previous EGFR-TKIs, ORR was 58.8\% and disease control rate was $97.1 \%$ in 34 patients with centrally confirmed T790M mutations. ${ }^{33}$

\section{Conclusion}

Three generations of EGFR TKIs have revolutionized the therapy of NSCLC patients with EGFRm ${ }^{+}$. Despite great progression in this field, treatment of the molecularly selected patient poses novel challenges, such as emergence of acquired resistance mostly mediated by T790M. Thirdgeneration EGFR TKIs have been designed to overcome resistance through covalent binding to the Cys 797 residue of the enzyme, and they are effective against most clinically relevant EGFR mutants while sparing wild-type EGFR. However, the high dependence of three generations of EGFR TKIs on this particular interaction means that additional mutation of Cys 797 results in poor inhibitory activity, which leads to tumor relapse in initially responding patients. ${ }^{34}$ In future, novel EGFR TKIs should be designed and developed for high inhibitory activities against the cysteine-mutated L858R/ T790M/C797S EGFR. Even if a cure for advanced lung cancer still remains out of reach, we can hope that in the near future, lung cancer may be well controlled under the power of precision medicine in genetically defined tumors.

\section{Acknowledgment}

This work was supported by the National Natural Science Foundation of China (81371678).

\section{Disclosure}

The author reports no conflicts of interest pertaining to this review.

\section{References}

1. Zhang H. Apatinib for molecular targeted therapy in tumor. Drug Des Devel Ther. 2015;9:6075-6081.

2. Russo A, Franchina T, Ricciardi GR, et al. A decade of EGFR inhibition in EGFR-mutated non small cell lung cancer (NSCLC): old successes and future perspectives. Oncotarget. 2015;6(29):26814-26825.

3. Liu YB, Zhao Y, Qin YX, Du XH, Wang Q, Lyu JX. A novel microfluidic device that integrates nucleic acid extraction, amplification, and detection to identify an EGFR mutation in lung cancer tissues. RSC Adv 2016;6(16):13399-13406.

4. Tiseo M, Bartolotti M, Gelsomino F, Bordi P. Emerging role of gefitinib in the treatment of non-small-cell lung cancer (NSCLC). Drug Des Devel Ther. 2010;4:81-98.

5. Zhang Q, Wang Z, Guo J, et al. Comparison of single-agent chemotherapy and targeted therapy to first-line treatment in patients aged 80 years and older with advanced non-small-cell lung cancer. Onco Targets Ther. 2015;8:893-898.

6. Villadolid J, Ersek JL, Fong MK, Sirianno L, Story ES. Management of hyperglycemia from epidermal growth factor receptor (EGFR) tyrosine kinase inhibitors (TKIs) targeting T790M-mediated resistance. Transl Lung Cancer Res. 2015;4(5):576-583.

7. Ercan D, Choi HG, Yun CH, et al. EGFR mutations and resistance to irreversible pyrimidine-based EGFR inhibitors. Clin Cancer Res. 2015; 21(17):3913-3923.

8. Sequist LV, Yang JC, Yamamoto N, et al. Phase III study of afatinib or cisplatin plus pemetrexed in patients with metastatic lung adenocarcinoma with EGFR mutations. J Clin Oncol. 2013;31(27):3327-3334.

9. Ramalingam SS, Blackhall F, Krzakowski M, et al. Randomized phase II study of dacomitinib (PF-00299804), an irreversible panhuman epidermal growth factor receptor inhibitor, versus erlotinib in patients with advanced non-small-cell lung cancer. J Clin Oncol.2012; 30(27):3337-3344.

10. Cross DA, Ashton SE, Ghiorghiu S, et al. AZD9291, an irreversible EGFR TKI, overcomes T790M-mediated resistance to EGFR inhibitors in lung cancer. Cancer Discov. 2014;4(9):1046-1061. 
11. Pirker R. Third-generation epidermal growth factor receptor tyrosine kinase inhibitors in advanced nonsmall cell lung cancer. Curr Opin Oncol. 2016;28(2):115-121.

12. Greig SL. Osimertinib: first global approval. Drugs. 2016;76(2): 263-273.

13. Shepherd FA, Rodrigues Pereira J, Ciuleanu T, et al; National Cancer Institute of Canada Clinical Trials Group. Erlotinib in previously treated non-small-cell lung cancer. N Engl J Med. 2005;353(2):123-132.

14. Mok TS, Wu YL, Thongprasert S, et al. Gefitinib or carboplatinpaclitaxel in pulmonary adenocarcinoma. NEngl J Med. 2009;361(10): 947-957.

15. Han JY, Park K, Kim SW, et al. First-SIGNAL: first-line single-agent iressa versus gemcitabine and cisplatin trial in never-smokers with adenocarcinoma of the lung. J Clin Oncol. 2012;30(10):1122-1128.

16. Zhou $\mathrm{C}, \mathrm{Wu} \mathrm{YL}, \mathrm{Chen} \mathrm{G}$, et al. Erlotinib versus chemotherapy as first-line treatment for patients with advanced EGFR mutation-positive non-small-cell lung cancer (OPTIMAL, CTONG-0802): a multicentre, open-label, randomised, phase 3 study. Lancet Oncol. 2011;12(8): 735-742.

17. Rosell R, Carcereny E, Gervais R, et al; Spanish Lung Cancer Group in collaboration with Groupe Français de Pneumo-Cancérologie and Associazione Italiana Oncologia Toracica. Erlotinib versus standard chemotherapy as first-line treatment for European patients with advanced EGFR mutation-positive non-small-cell lung cancer (EURTAC): a multicentre, open-label, randomised phase 3 trial. Lancet Oncol. 2012; 13(3):239-246.

18. Shi Y, Zhang L, Liu X, et al. Icotinib versus gefitinib in previously treated advanced non-small-cell lung cancer (ICOGEN): a randomised, double-blind phase 3 non-inferiority trial. Lancet Oncol. 2013;14(10): 953-961.

19. Yap TA, Vidal L, Adam J, et al. Phase I trial of the irreversible EGFR and HER2 kinase inhibitor BIBW 2992 in patients with advanced solid tumors. J Clin Oncol. 2010;28(25):3965-3972.

20. Miller VA, Hirsh V, Cadranel J, et al. Afatinib versus placebo for patients with advanced, metastatic non-small-cell lung cancer after failure of erlotinib, gefitinib, or both, and one or two lines of chemotherapy (LUXLung 1): a phase 2b/3 randomised trial. Lancet Oncol. 2012;13(5): 528-538.

21. Yang JC, Shih JY, Su WC, et al. Afatinib for patients with lung adenocarcinoma and epidermal growth factor receptor mutations (LUX-Lung 2): a phase 2 trial. Lancet Oncol. 2012;13(5):539-548.

22. Kwak EL, Sordella R, Bell DW, et al. Irreversible inhibitors of the EGF receptor may circumvent acquired resistance to gefitinib. Proc Natl Acad Sci U S A. 2005;102(21):7665-7670.
23. Sequist LV, Besse B, Lynch TJ, et al. Neratinib, an irreversible panErbB receptor tyrosine kinase inhibitor: results of a phase II trial in patients with advanced non-small-cell lung cancer. J Clin Oncol. 2010; 28(18):3076-3083.

24. Engelman JA, Zejnullahu K, Gale CM, et al. PF00299804, an irreversible pan-ERBB inhibitor, is effective in lung cancer models with EGFR and ERBB2 mutations that are resistant to gefitinib. Cancer Res. 2007;67(24):11924-11932.

25. Jänne PA, Ou SH, Kim DW, et al. Dacomitinib as first-line treatment in patients with clinically or molecularly selected advanced non-smallcell lung cancer: a multicentre, open-label, phase 2 trial. Lancet Oncol. 2014;15(13):1433-1441.

26. Ellis PM, Shepherd FA, Millward M, et al; NCIC CTG; Australasian Lung Cancer Trials Group; NCI Naples Clinical Trials Unit. Dacomitinib compared with placebo in pretreated patients with advanced or metastatic non-small-cell lung cancer (NCIC CTG BR.26): a double-blind, randomised, phase 3 trial. Lancet Oncol. 2014;15(12):1379-1388.

27. Jiang $\mathrm{T}, \mathrm{Zhou} \mathrm{C}$. Clinical activity of the mutant-selective EGFR inhibitor AZD9291 in patients with EGFR inhibitor-resistant non-small cell lung cancer. Transl Lung Cancer Res. 2014;3(6):370-372.

28. Yosaatmadja Y, Silva S, Dickson JM, et al. Binding mode of the breakthrough inhibitor AZD9291 to epidermal growth factor receptor revealed. J Struct Biol. 2015;192(3):539-544.

29. Jänne PA, Yang JC, Kim DW, et al. AZD9291 in EGFR inhibitor-resistant non-small-cell lung cancer. $N$ Engl J Med. 2015;372(18):1689-1699.

30. Yang J, Ramalingam SS, Jänne PA, Cantarini M, Mitsudomi T. LBA2_PR: osimertinib (AZD9291) in pre-treated pts with T790Mpositive advanced NSCLC: updated Phase 1 (P1) and pooled Phase 2 (P2) results. J Thorac Oncol. 2016;11(4 suppl):S152-S153.

31. Walter AO, Sjin RT, Haringsma HJ, et al. Discovery of a mutantselective covalent inhibitor of EGFR that overcomes T790M-mediated resistance in NSCLC. Cancer Discov. 2013;3(12):1404-1415.

32. Sequist LV, Soria JC, Goldman JW, et al. Rociletinib in EGFR-mutated non-small-cell lung cancer. N Engl J Med. 2015;372(18):1700-1709.

33. Park K, Lee J-S, Lee KH, et al. Updated safety and efficacy results from phase I/II study of HM61713 in patients (pts) with EGFR mutation positive non-small cell lung cancer (NSCLC) who failed previous EGFR-tyrosine kinase inhibitor (TKI). J Clin Oncol. 2015; 33(15 suppl):8084.

34. Günther M, Juchum M, Kelter G, Fiebig H, Laufer S. Lung cancer: EGFR inhibitors with low nanomolar activity against a therapy-resistant L858R/T790M/C797S mutant. Angew Chem Int Ed Engl. 2016;55(36): 10890-10894
Drug Design, Development and Therapy

\section{Publish your work in this journal}

Drug Design, Development and Therapy is an international, peerreviewed open-access journal that spans the spectrum of drug design and development through to clinical applications. Clinical outcomes, patient safety, and programs for the development and effective, safe, and sustained use of medicines are the features of the journal, which

\section{Dovepress}

has also been accepted for indexing on PubMed Central. The manuscript management system is completely online and includes a very quick and fair peer-review system, which is all easy to use. Visit http://www.dovepress.com/testimonials.php to read real quotes from published authors. 